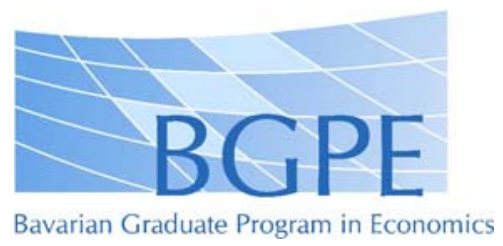

BGPE Discussion Paper

No. 61

\title{
Acquisitions in a Patent Contest Model with Large and Small Firms
}

\author{
Robin Kleer
}

June 2008

ISSN 1863-5733

Editor: Prof. Regina T. Riphahn, Ph.D.

Friedrich-Alexander-University Erlangen-Nuremberg

(c) Robin Kleer 


\title{
Acquisitions in a Patent Contest Model with Large and Small Firms *
}

\author{
Robin Kleer ${ }^{\dagger}$ \\ University of Würzburg and Michigan State University
}

June 20, 2008

\begin{abstract}
Big companies and small innovation factories possess different advantages in a patent contest. While large firms typically have a better access to product markets, small firms often have a superior R\&D efficiency. In this paper I model a patent contest with asymmetric firms. In a pre-contest acquisition game large firms bid sequentially for small firms to combine respective advantages. Sequential bidding allows the first large firm to wait strategically and let the other firm acquire. For low efficiencies this leads to an asymmetric market structure even though the initial situation is symmetric. Furthermore, acquisitions increase the chances for a successful innovation.
\end{abstract}

Keywords: patent contest, sequential acquisitions

JEL Classification: O31, L24, G34

${ }^{*}$ I am grateful to Norbert Schulz for continuous guidance, encouragement and assistance. I would also like to thank Peter Welzel, Jay Pil Choi and seminar participants at the 4th BGPE research workshop and the graduate student seminar at Michigan State University for helpful comments.

${ }^{\dagger}$ University of Würzburg, Industrial Economics (chair: Norbert Schulz) and Bavarian Graduate Program in Economics, Sanderring 2, 97070 Würzburg, Germany. Phone: +49 (0) 931 - 31-2957, e-mail: robin.kleer@uni-wuerzburg, web: www.vwl.uni-wuerzburg.de/vwl3. 


\section{Introduction}

In R\&D intensive industries firms often do not rely only on their own research capabilities but use the results of competitors via licensing or even acquire other firms to directly benefit from their innovation efforts. Theoretical literature, based on transaction costs economies and property rights (Coase (1937), Arrow (1962)), argues that internal development and external sourcing are substitutes. Empirical evidence is mixed. Veugelers and Cassiman (1999) show that - especially large companies - use both internal and external sources for innovations. Roberts and Berry (1985) on the other hand provide evidence that acquisition of small technology based companies is often used to get access to innovations.

Different types of firms are likely to possess different advantages in a patent contest. While large firms typically have better access to product markets, small firms often have a superior R\&D efficiency. The aim of this paper is to model these advantages and use them to explain acquisitions of small firms in innovative industries.

There are several empirical studies showing the superior R\&D efficiency of small firms. Acs and Audretsch (1990) show empirically that small firms contribute as many innovations as large firms and - in terms of innovations per employee - outperform large firms. They use a dataset by the U.S. Small Business Administration consisting of 8,074 innovations introduced in the United States in 1982. Van Dijk et al. (1995), Rothwell (1989) and Santarelli and Sterlacchini (1990) provide similar results for Netherlands, UK and Italy, respectively.

Other studies from Cohen and Levin (1989) and Kamien and Schwartz (1982) show that small firms can keep up with large firms in the field of innovation. They spend relatively more on $R \& D$ and are more efficient in using this $R \& D$ for innovative output.

An explanation for this superior R\&D efficiency may be the less bureaucratic atmosphere in small firms. Creative minds tend to dislike paperwork and may be frustrated and therefore less effective in a large firm where reporting and formal documentation is necessary (see Ernst and Vitt (2000)). Furthermore, the organization of internal communication - which can be less formal in small companies - encourages faster and more creative ways of problem solving and a fast adaption to changes in the external environment (see Rothwell and Zegveld (1982)).

Rothwell (1989) explains the better position in the product market of large firms with their comprehensive distribution networks and service facilities. Economies of scope puts them in a superior position. They can offer a range of complementary products and use their market power of existing products. Moreover, in case of a patent infringement they can afford to litigate to defend their patents and avoid misuse. What is more, the marketing of complex high technology goods often requires a qualified after sales service difficult to provide for small firms.

These different advantages immediately lead to the question of cooperations between these firms. Lindholm (1996a, 1996b) shows for a Swedish case that small firms actively 
engage in being taken over by large firms to get access to international markets and use their global market presence. A recent analysis of an acquisition in the optics industry also shows the problem of small firms (Competition Commission (2004)). Bio Rad's microscopes business unit was acquired by Zeiss. The main reason for this acquisition was a patent dispute between Zeiss and Bio Rad which has been solved through this merger. Although Bio Rad's business unit was in possession of important licences in 3D light microscope systems the unit was not profitable. One of the reasons was that this unit was not providing own microscope stands but only equipping competitors' stands with their technique. A very critical detail in the commission's analysis is the conclusion that Bio Rad would not remain an independent supplier in the long run whether or not the merger takes place. The small business unit had not enough capacities to survive in this market alone. Therefore - if the merger was blocked - Bio Rad's microscopes business unit would either drop out of the market or eventually get acquired by a different competitor.

This paper is related to the patent races and patent contest literature. Reinganum (1989) provides a very good overview of that literature up to that point. More recent literature on patent races focuses on optimal patent design (Denicolò (1996)) and races with multiple prizes (Dorazelski (2003), Hörner (2004)). In the latter literature, firms' past $R \& D$ efforts influence their chances in a new race. This improves the description of the dynamics of innovation competition. Zachau (1987) analyzes mergers using a simple patent race model. Firms are symmetric at start but a merger is assumed to have synergetic effects and increases R\&D efficiency of the merged firm. He allows for mergers of any numbers of firms and shows that in a $n$-firm industry the number of firms merging that maximizes merged firm's profits is typically less than $n$. Jost and van der Velden (2006) provide a similar analysis using a contest model proposed by Dixit (1987). As in Zachau's paper a merger is assumed to increase R\&D efficiency of the merged firm. They show that only little efficiency gains are needed to make a bilateral merger profitable. They do also show that in the presence of knowledge spillovers more efficiency gains are needed to make a merger profitable. In contrast to both these papers, my model starts with an asymmetric situation where firms possess different advantages. Furthermore, I allow for a sequence of acquisitions to analyze the strategic effect of a merger.

Economic and management literature seeks to explain why mergers often happen in waves. There are nonstrategic explanations of merger waves that attribute the occurrence of these waves to exogenous factors like changes in competition policy (Stigler (1950), Bittlingmayer (1985) or the business cycle (van Wegberg (1994)). On the other hand there are strategic explanations how past acquisitions affect future mergers. A recent example from the telecommunications industry is the acquisition of Tele Atlas by TomTom 1 which at least partly triggered the acquisition of Tele Atlas' competitor Navteq

\footnotetext{
${ }^{1}$ See for example Tele Atlas' press release under: http://www.teleatlas.com/WhyTeleAtlas/Pressroom/PressReleases/TA_CT018103.
} 
by Nokia $2^{2}$ Nilssen and Sørgard (1998) analyze sequential acquisitions, in particular the strategic impact of an acquisition on subsequent merger decisions. The authors show in a linear Cournot model that the decision to merge or not to merge can either trigger or prevent follow-up merger. I do also analyze the strategic effect of an acquisition but with focus on the innovation market.

In this paper, I model a patent contest with asymmetric competitors. There are small research firms that have a better R\&D efficiency and large firms that benefit from their better access to the product market. I use the Dixit (1987) model to describe the contest but in contrast to Jost and van der Velden (2006) I allow for initial differences in R\&D efficiency. To the best of my knowledge there exists no paper that deals with this kind of asymmetry in an $\mathrm{R} \& \mathrm{D}$ contest ${ }^{3}$ The firms compete for an exclusive patent that gives them a fixed return in the product market. In contrast to Jost and van der Velden, the amount of this return depends on the product market power of the winning firm. Prior to the innovation stage, I allow for acquisitions of small firms by large firms. Large firms sequentially bid for small firms. After an acquisition the merged firm combines the respective advantages of large and small firms.

The paper is organized as follows. The next section presents the patent contest and the way respective advantages for large and small firms are modeled. Then the game structure is described and the game is solved. The robustness section analyzes the impact of the timing on results of the game. The final section concludes, discusses limitations of my model and points out interesting topics for further research.

\section{Model}

Firms are competing for an exclusive prize $V_{i}$. They simultaneously choose an effort level $z_{i}$ which affects their own - and thus competitors' - chances of winning the contest. The probability of winning is the own effort level divided by the sum of all efforts multiplied by an innovation efficiency parameter, thus

$$
p_{i}=\alpha_{i} \cdot \frac{z_{i}}{\sum z_{j}} \quad i=1, \ldots, n .
$$

Throughout the paper I assume that large firms have advantages in the product market by realizing a value $V_{L}$ if they win the contest, while small firms only realize a value $V_{S}<V_{L}$. On the other hand, small firms have a greater chance of winning the contest with the same investment in R\&D, i.e. $\alpha_{S}>\alpha_{L}$. I assume that overall efficiency is the

\footnotetext{
${ }^{2}$ See for example Nokia's press release under: http://www.nokia.com/A4136002?newsid=-6233.

${ }^{3}$ Asymmetry in an $\mathrm{R} \& \mathrm{D}$ race is often modeled with an incumbent and an entrant in a market, usually with some advantages for the incumbent. See for example Gilbert and Newberry (1982) or Harris and Vickers (1985).
} 
same for large and small firms 4

$$
\alpha_{S} \cdot V_{S}=\alpha_{L} \cdot V_{L}
$$

or

$$
\alpha_{S}=x \cdot \alpha_{L} \text { and } V_{S}=\frac{V_{L}}{x}
$$

where $x>1$ is a measure of difference between large and small firms which is the source of efficiencies of mergers. Throughout the paper, $x$ is therefore called efficiency parameter. In the following section I first describe the time structure of the game. Then the R\&D games for different outcomes of the acquisition game are analyzed. Finally, the game is solved by backward induction to find sub-game perfect strategies for the bidding of large firms and acceptance decisions of small firms.

\subsection{Sequential acquisitions}

In this section I analyze sequential acquisitions. An acquisition is assumed to have the following effect: The large firm quits its own research and only uses the small firm's research facilities. Thus, the firm can now operate with the high research ability $\alpha_{S}$ and at the same time using the large firm's market power, meaning that winning the contest leads to a prize $V_{L}$. The number of active firms in the market is reduced by one. This way of modeling the acquisition can also be interpreted as ex ante licensing or contract research ${ }^{6}$ The acquisition has both a positive and a negative effect on the merged company. The positive effect is that it operates now more efficiently than its competitors in the innovation or the product market. The negative effect is that the former two firms now only operate as one. 7 Without efficiencies, this leads to a loss in terms of expected profits for the merged company. The reason is that before the merger, both the large and the small firm had a chance to win the contest while now there is only one firm competing in the contest. The outsiders benefit from the reduction of firms but they suffer from the created efficiencies by the merged company. A second acquisition by the same large firm has no effect on its $R \& D$ efficiency. It just reduces the number of competitors again and prevents the other large firm from enjoying efficiencies of an acquisition. It is assumed that a large firm cannot buy the other large firm for reasons of competition law.

In the acquisition game large firms successively bid for small firms. After each bid the small firm decides whether to accept the offer or not. I assume that the game starts with

\footnotetext{
${ }^{4}$ This assumption is made to keep the model analytically tractable and it is clearly restricting. However, from my results tendencies for more general cases can be deviated. If overall efficiency is different, the efficiency effect of an acquisition is increased.

${ }^{5}$ To simplify notation in the following $\alpha_{S}:=\alpha$ and $V_{S}:=V$ is used.

${ }^{6}$ Important for my way of modeling is that the small firm still performs R\&D in the same way as before the acquisition. Otherwise, the superior R\&D efficiency would be lost.

${ }^{7}$ Without efficiencies investment of the merged firm is smaller than combined investment of the two former independent firms. The result is comparable to the output reduction and subsequent reduced profit of a merged firm in the Salant et al. (1983) model without cost efficiencies.
} 
the first large firm's bid for the first small firm. Each large firm only bids one time for each small firm. The acquisition game ends either when both small firms are acquired or both large firms made their bids for both small firms 8 In the following I call the large firms $L_{1}$ and $L_{2}$ and the small firms $S_{1}$ and $S_{2}$. After the acquisition game the remaining independent firms make their investments in the patent contest. The game structure is summarized in figure 1. Each decision point is numbered to make reference in the equilibrium section. Large firms have the possibility to bid continuously, $p_{i j} \in[0, \infty)$. Strategies for small firms are $\mathrm{A}$ (ccepting) and $\mathrm{D}$ (enying) the offers.

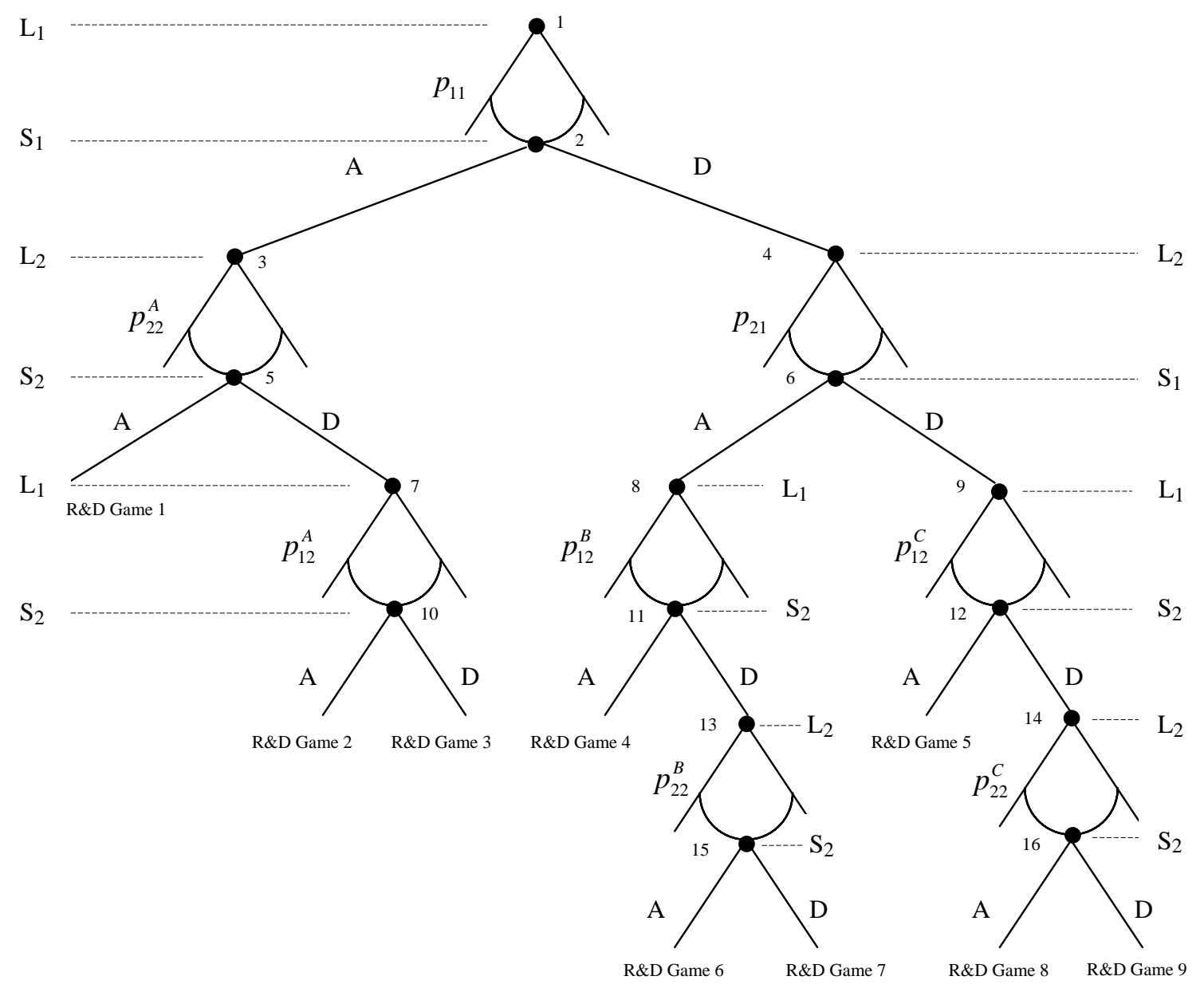

Figure 1: Game Structure

\footnotetext{
${ }^{8}$ The resulting market structure in equilibrium is the same for most parameter values if the acquisition game is simplified in a way that large firms just pays the current expected profits of small firms when it wants to acquire. Thus, if small firms do not expect further changes in the market structure and act myopic in the acquisition game.
} 


\subsubsection{R\&D Games}

In this section optimal investment strategies and resulting expected profits of the $\mathrm{R} \& \mathrm{D}$ game for all possible outcomes of the acquisition game are derived. Firms are assumed to maximize their expected profits

$$
E\left[\pi_{i}\right]=p_{i} \cdot V_{i}-z_{i}=\alpha_{i} \cdot \frac{z_{i}}{\sum z_{j}} \cdot V_{i}-z_{i} \quad i=1, \ldots, n
$$

which yields the first order conditions:

$$
\alpha_{i} \cdot \frac{\sum_{j \neq i}^{n} z_{j}}{\left(\sum_{j} z_{j}\right)^{2}} \cdot V_{i}-1 \stackrel{!}{=} 0 \quad i=1, \ldots, n .
$$

Firms thus increase their investments in R\&D to improve their chances to win the contest until marginal benefits of the investments equal marginal costs.

If no firm decides to merge, there are 4 active firms in the market. Two identical small and large firms, respectively. This is the situation in R\&D game 9. With (2.1) first order conditions 2.3 can be solved for

$$
z_{i}=\frac{\alpha \cdot V}{16} \quad i=1, \ldots 4
$$

Thus, both types of firms invest the same in $R \& D$ as their overall efficiency is the same. Inserting equilibrium investments in the profit functions 2.2 yields 9

$$
E\left[\pi_{S}^{R \& D_{9}}\right]=E\left[\pi_{L}^{R \& D_{9}}\right]=\frac{\alpha V}{16} .
$$

In R\&D games 1 and 4 each of the small firms is acquired by one large firm, i.e. we have a situation where only 2 identical firms remain in the market. Both have small firms' R\&D efficiency $\alpha$ and large firms' product market efficiency $V_{L}=x \cdot V$. Using these parameters in 2.3 yields the first order conditions

$$
\alpha \frac{z_{j}}{\left(z_{i}+z_{j}\right)^{2}}-\frac{1}{x \cdot V} \stackrel{!}{=} 0 \quad i=1,2 .
$$

With $z_{1}=z_{2}$ due to symmetry equations 2.4 can be solved for

$$
z_{1}=z_{2}=\frac{\alpha x V}{4} .
$$

Resulting expected profits are

$$
E\left[\pi_{M}^{R \& D_{1}}\right]=\frac{\alpha x V}{4} .
$$

Small firms get the price the large firms bid in the acquisition game as payoffs.

In R\&D games 3, 5, 7 and 8 only one large firm acquires one small firm, the other 2 firms stay independent. The respective first order conditions for the small, merged and

\footnotetext{
${ }^{9} \mathrm{I}$ use the indices $\mathrm{S}, \mathrm{L}$ and $\mathrm{M}$ to denote small, large and merged firms respectively.
} 
large firm are

$$
\begin{gathered}
\alpha \frac{z_{L}+z_{M}}{\left(z_{S}+z_{L}+z_{M}\right)^{2}}-\frac{1}{V} \stackrel{!}{=} 0 \\
\alpha \frac{z_{S}+z_{L}}{\left(z_{S}+z_{L}+z_{M}\right)^{2}}-\frac{1}{x V} \stackrel{!}{=} 0 \\
\frac{\alpha}{x} \frac{z_{S}+z_{M}}{\left(z_{S}+z_{L}+z_{M}\right)^{2}}-\frac{1}{x V} \stackrel{!}{=} 0 .
\end{gathered}
$$

Solving for $z_{S}, z_{L}$ and $z_{M}$ yields

$$
\begin{aligned}
z_{S} & =z_{L}=\frac{2 \alpha x V}{(1+2 x)^{2}} \\
z_{M} & =\frac{2 \alpha x V}{(1+2 x)^{2}}(2 x-1) .
\end{aligned}
$$

It is easy to see that the merged firm invest more than its competitors. Resulting profits are

$$
\begin{aligned}
& E\left[\pi_{S}^{R \& D_{3}}\right]=E\left[\pi_{L}^{R \& D_{3}}\right]=\frac{\alpha V}{(1+2 x)^{2}} \\
& E\left[\pi_{M}^{R \& D_{3}}\right]=\frac{\alpha x V}{(1+2 x)^{2}}(2 x-1)^{2} .
\end{aligned}
$$

As with investments, the expected profit of the merged firm is larger since $x>1$. The acquired small firm gets the price bid in the acquisition game as payoff.

In R\&D games 2 and 6 one large firm acquires both small firms. There is thus one firm with high and one firm with low R\&D efficiency in the market. Both firms have high product market efficiency. That yields the first order conditions

$$
\begin{aligned}
& \frac{\alpha}{x} \frac{z_{M}}{\left(z_{L}+z_{M}\right)^{2}}-\frac{1}{x V} \stackrel{!}{=} 0 \\
& \alpha \frac{z_{L}}{\left(z_{L}+z_{M}\right)^{2}}-\frac{1}{x V} \stackrel{!}{=} 0 .
\end{aligned}
$$

Solving for $z_{L}$ and $z_{M}$ yields

$$
\begin{aligned}
z_{L} & =\frac{\alpha x V}{(1+x)^{2}} \\
z_{M} & =\frac{\alpha x^{2} V}{(1+x)^{2}}
\end{aligned}
$$

Resulting expected profits are

$$
\begin{aligned}
& E\left[\pi_{L}^{R \& D_{2}}\right]=\frac{\alpha V}{(1+x)^{2}} \\
& E\left[\pi_{M}^{R \& D_{2}}\right]=\frac{\alpha x^{3} V}{(1+x)^{2}} .
\end{aligned}
$$

As before in the triopoly game, the more efficient firm invests more in R\&D and has higher expected profits. Small firms get the price the acquiring large firm bid in the acquisition game as payoffs.

If a large firm acquired one or two small firms, the price it payed has to be subtracted from its expected profits in order to make payoffs comparable. 


\subsubsection{Equilibria}

Large firms decide on their bid in each decision point; small firms make their acceptance decisions ${ }^{10}$ In the acquisition game there are two critical barriers for the bids of large firms and acceptance decisions of small firms. The first is the profit of an independent firm if no acquisition takes place: $p_{N}=\frac{\alpha V}{16}$, the second is the profit of an outsider in a triopoly: $p_{O}=\frac{\alpha V}{(1+2 x)^{2}}{ }^{11}$ These are the two possible expected profits a small firm can achieve if it has not been acquired and remains an independent firm in the R\&D game.

Proposition 1. In equilibrium the acquisition game ends in a symmetric duopoly with accepted bids $p_{11}=p_{22}=p_{O}$ for $x \geq 1.18731$, in an asymmetric duopoly with accepted bids $p_{21}=p_{22}=p_{O}$ for $1.18731>x \geq 1.05678$ and accepted bids $p_{21}=p_{N}, p_{22}=p_{O}$ for $1.0333>x$, and in a triopoly where only $S_{2}$ is acquired for $p_{22}=p_{N}$ if $1.05678>$ $x \geq 1.0333$.

Proof. To prove proposition 1, the acquisition game is solved by backward induction. At decision point $16 S_{2}$ has to decide whether to accept the price $p_{22}^{C}$ offered by $L_{2}$ or denying the offer and getting a payoff of $\frac{\alpha V}{16}$. Thus, $S_{2}$ accepts every offer $p_{22}^{C} \geq p_{N}$ and denies any other offer.

Expecting this decision from $S_{2}, L_{2}$ makes his offer in decision point 14 . If $S_{2}$ denies the offer, the game ends without any acquisition and $L_{2}$ gets the payoff $\frac{\alpha V}{16}$. If $S_{2}$ accepts, $L_{2}$ gets the payoff of R\&D game 8, the triopoly with one merged, one small and one large firm. If $L_{2}$ decides to acquire, it makes the lowest offer $S_{2}$ accepts, i.e. $p_{22}^{C}=p_{N}$. Thus, $L_{2}$ decides to make an offer if

$$
\frac{\alpha x V}{(1+2 x)^{2}}(2 x-1)^{2}-\frac{\alpha V}{16} \geq \frac{\alpha V}{16} .
$$

This inequality holds for $x \geq 1.0333$.

If $S_{2}$ accepts the offer in decision point 12, it gets the payoff $p_{12}^{C}$. If not, it either gets $p_{22}^{C}=p_{N}$ if $x \geq 1.0333$ resulting from an acceptable offer by $L_{2}$ or $\frac{\alpha V}{16}$ if $x<1.0333$ as an independent firm in R\&D game 9 . Thus, $S_{2}$ accepts any offer by $L_{1}$ that is greater or equal than $p_{N}$.

In decision point $9 L_{1}$ has to offer at least $p_{12}^{C}=p_{N}$ if it wants $S_{2}$ to accept. If $S_{2}$ accepts the bid, $L_{1}$ 's payoff is

$$
\frac{\alpha x V}{(1+2 x)^{2}}(2 x-1)^{2}-p_{12}^{C} .
$$

If $S_{2}$ denies the offer, $L_{1}$ gets the payoff of an outsider in R\&D game 8 when $x \geq 1.0333$ i.e. in the situation where $L_{2}$ decides to acquire in decision point 14 . This payoff is

$$
\frac{\alpha V}{(1+2 x)^{2}}
$$

\footnotetext{
${ }^{10}$ If a firm is indifferent between acquiring and not acquiring, I assume that the firm is acquiring; if a small firm is indifferent between accepting and denying an offer, I assume it is accepting.

${ }^{11}$ Note that $p_{N} \leq p_{O} \Leftrightarrow x \leq 1.5$. Thus, small firms only prefer $p_{N}$ to $p_{O}$ for very high efficiencies.
} 
If $x<1.0333, S_{1}$ gets $\frac{\alpha V}{16}$ as payoff. Consider first the case $x \geq 1.0333: L_{1}$ acquires if

$$
\frac{\alpha x V}{(1+2 x)^{2}}(2 x-1)^{2}-\frac{\alpha V}{16} \geq \frac{\alpha V}{(1+2 x)^{2}} .
$$

This inequality holds for $x \geq 1.10933$. In the case $x<1.0333 L_{1}$ acquires if

$$
\frac{\alpha x V}{(1+2 x)^{2}}(2 x-1)^{2}-\frac{\alpha V}{16} \geq \frac{\alpha V}{16} .
$$

This inequality never holds since $x<1.0333$. Thus, $L_{1}$ decides to acquire in decision point 9 if $x \geq 1.10933$.

In decision point $15 S_{2}$ gets the payoff of an outsider in R\&D game 7 if it denies the offer. Therefore $S_{2}$ accepts every offer $p_{22}^{B} \geq p_{O}$.

In decision point $13 L_{2}$ has already acquired $S_{1}$ for $p_{21}$. If $L_{2}$ acquires, $S_{1}$, the situation is an asymmetric duopoly where $L_{2}$ has acquired both small firms. $L_{2}$ 's payoff if it acquires is

$$
\frac{\alpha x^{3} V}{(1+x)^{2}}-p_{21}-p_{22}^{B}
$$

where $p_{22}^{B}=p_{O}$ is the lowest offer $S_{2}$ accepts. If $L_{2}$ does not acquire, its payoff is the payoff of the merged firm in R\&D game 7 minus the price payed for $S_{1}$ :

$$
\frac{\alpha x V}{(1+2 x)^{2}}(2 x-1)^{2}-p_{21} \text {. }
$$

Thus, $L_{2}$ acquires if

$$
\frac{\alpha x^{3} V}{(1+x)^{2}}-p_{21}-\frac{\alpha V}{(1+2 x)^{2}} \geq \frac{\alpha x V}{(1+2 x)^{2}}(2 x-1)^{2}-p_{21} .
$$

This inequality holds for every $x \geq 1$ and therefore $L_{2}$ always bids $p_{22}^{B}=p_{O}$ and acquires $S_{2}$ in decision point 13.

In decision point $11 S_{2}$ accepts any offer $p_{12}^{B} \geq p_{O}$.

In decision point $8 L_{1}$ has to offer least $p_{12}^{B}=p_{O}$ if it wants $S_{2}$ to accept. If $S_{2}$ accepts, the resulting situation is $\mathrm{R} \& \mathrm{D}$ game 4 , a symmetric duopoly. If $S_{2}$ denies the offer, $L_{1}$ gets the profit of an outsider in an asymmetric duopoly in R\&D game 6 since $L_{2}$ always makes an offer that $S_{2}$ accepts in decision point 13. $L_{1}$ therefore decides to offer $p_{12}^{B}=p_{O}$ and to acquire $S_{2}$ if

$$
\frac{\alpha x V}{4}-\frac{\alpha V}{(1+2 x)^{2}} \geq \frac{\alpha V}{(1+x)^{2}} .
$$

This inequality holds for $x \geq 1.18731$.

If $S_{1}$ denies the offer in decision point 6 , the acquisition game ends in R\&D game 8 for $x \geq 1.0333$ and in $\mathrm{R} \& \mathrm{D}$ game 9 for $x<1.0333$. Thus $S_{1}$ accepts every offer $p_{21} \geq p_{O}$ for $x \geq 1.0333$ and every offer $p_{21} \geq p_{N}$ for $x<1.0333$.

If $L_{2}$ decides to acquire $S_{1}$ in decision point 4 , the acquisition game ends in R\&D game 4 for $x \geq 1.18731$ and in $\mathrm{R} \& \mathrm{D}$ game 6 for $x<1.18731$. If $L_{2}$ does not acquire $S_{1}$, the acquisition game ends in R\&D game 5 for $x \geq 1.0933$, in $\mathrm{R} \& \mathrm{D}$ game 8 for 
$1.10933>x \geq 1.0333$ and in R\&D game 9 for $x<1.0333$. Consider first the case $x \geq 1.18731$ : The payoff for $L_{2}$ in $\mathrm{R} \& \mathrm{D}$ game 4 is $\frac{\alpha x V}{4}-p_{21}$; in $\mathrm{R} \& \mathrm{D}$ game 5 it is $\frac{\alpha V}{(1+2 x)^{2}}$. The payoff in R\&D game 4 is larger for the lowest accepted offer $p_{21}$. For $x \geq 1.18731 L_{2}$ therefore bids $p_{21}=p_{O}$ and acquires $S_{1}$. The next case to consider is $1.18731>x \geq 1.10933$ : The payoff for $L_{2}$ if it acquires $S_{1}$ is given by $\mathrm{R} \& \mathrm{D}$ game 6 and is thus $\frac{\alpha x^{3} V}{(1+x)^{2}}-p_{21}-p_{22}^{B}$, where $p_{22}^{B}=p_{O}$ and the lowest accepted offer is $p_{21}=p_{O}$. If $L_{2}$ does not acquire, its payoff is given by $\mathrm{R} \& \mathrm{D}$ game 5 and it is $\frac{\alpha V}{(1+2 x)^{2}}$. Thus, $L_{2}$ acquires if

$$
\frac{\alpha x^{3} V}{(1+x)^{2}}-2 \cdot \frac{\alpha V}{(1+2 x)^{2}} \geq \frac{\alpha V}{(1+2 x)^{2}} \text {. }
$$

This inequality holds for every $1.18731>x \geq 1.10933$. The third case is $1.10933>x \geq$ 1.0333: The payoff for $L_{2}$ if it acquires is the same as in the previous case. If $L_{2}$ does not acquire, its payoff is given by $\mathrm{R} \& \mathrm{D}$ game 8 and it is $\frac{\alpha x V}{(1+2 x)^{2}}(2 x-1)^{2}-p_{22}^{C}$ with $p_{22}^{C}=p_{N}$. Thus, $L_{2}$ acquires if

$$
\frac{\alpha x^{3} V}{(1+x)^{2}}-2 \cdot \frac{\alpha V}{(1+2 x)^{2}} \geq \frac{\alpha x V}{(1+2 x)^{2}}(2 x-1)^{2}-\frac{\alpha V}{16} .
$$

This inequality holds for $x \geq 1.05678$. The last case to consider is $x<1.0333$. The payoff for $L_{2}$ if it acquires is again given by $\mathrm{R} \& \mathrm{D}$ game 6 , but $L_{2}$ only has to pay $p_{21}=p_{N}$ to make $S_{1}$ accept the offer. If $L_{2}$ does not acquire, its payoff is given by R\&D game 9 and it is $\frac{\alpha V}{16}$. Thus, $L_{2}$ acquires if

$$
\frac{\alpha x^{3} V}{(1+x)^{2}}-\frac{\alpha V}{(1+2 x)^{2}}-\frac{\alpha V}{16} \geq \frac{\alpha V}{16} .
$$

This inequality holds for every $x<1.0333$. Thus, in decision point $4 L_{2}$ bids $p_{21}=p_{O}$ and acquires $S_{1}$ for $x \geq 1.05678$, does not acquire $S_{1}$ for $1.05678>x \geq 1.0333$ and bids $p_{21}=p_{N}$ and acquires $S_{1}$ for $x<1.0333$.

In decision point $10 S_{2}$ accepts every offer that gives it a higher payoff than the payoff as an outsider in R\&D game 3 . Thus, $S_{2}$ accepts every offer $p_{12}^{A} \geq p_{O}$.

In decision point $7 L_{1}$ has already acquired $S_{1}$ for $p_{11}$. If $L_{1}$ acquires $S_{2}, L_{1}$ is the merged firm in R\&D game 2 and has a payoff $\frac{\alpha x^{3} V}{(1+x)^{2}}-p_{12}^{A}-p_{11}$, where the lowest accepted offer is $p_{12}^{A}=p_{O}$. If it decides not to acquire, its payoff is the one of the merged form in a triopoly, i.e $\frac{\alpha x V}{(1+2 x)^{2}}(2 x-1)^{2}-p_{11}$. Thus, $L_{1}$ acquires if

$$
\frac{\alpha x^{3} V}{(1+x)^{2}}-\frac{\alpha V}{(1+2 x)^{2}} \geq \frac{\alpha x V}{(1+2 x)^{2}}(2 x-1)^{2} .
$$

This inequality always holds and thus $L_{1}$ always bids $p_{12}^{A}=p_{O}$ and acquires $S_{2}$ in decision point 7 .

In decision point $5 S_{2}$ accepts every offer $p_{22}^{A} \geq p_{O}$.

In decision point $3 L_{2}$ can decide to acquire $S_{2}$ and create a symmetric duopoly in $\mathrm{R} \& \mathrm{D}$ game 1 or not to acquire $S_{2}$ and become the outsider in the asymmetric duopoly in $\mathrm{R} \& \mathrm{D}$ game 2 . If $L_{2}$ acquires, its payoff is $\frac{\alpha x V}{4}-p_{22}^{A}$, where the lowest accepted offer 
is $p_{22}^{A}=p_{O}$. If $L_{2}$ does not acquire, its payoff is $\frac{\alpha V}{(1+x)^{2}}$ Thus, $L_{2}$ acquires if

$$
\frac{\alpha x V}{4}-\frac{\alpha V}{(1+2 x)^{2}} \geq \frac{\alpha V}{(1+x)^{2}}
$$

This inequality holds for $x \geq 1.18731$ and therefore $L_{2}$ acquires $S_{2}$ for $x \geq 1.18731$ in decision point 3 .

If $S_{1}$ denies the offer in decision point 2 , the acquisition game ends with a payoff of $\frac{\alpha V}{(1+2 x)^{2}}$ for $S_{1}{ }^{12}$ Thus, $S_{1}$ accepts every offer $p_{11} \geq p_{O}$.

If $L_{1}$ decides to acquire in decision point 1 , the acquisition game ends with $\mathrm{R} \& \mathrm{D}$ game 1 for $x \geq 1.18731$ and with $\mathrm{R} \& \mathrm{D}$ game 2 if $x<1.18731$. If $L_{1}$ decides not to acquire, the acquisition game ends with $\mathrm{R} \& \mathrm{D}$ game 4 for $x \geq 1.18731$, with $\mathrm{R} \& \mathrm{D}$ game 6 for $1.18731>x \geq 1.05678$ or $x<1.0333$ and with $\mathrm{R} \& \mathrm{D}$ game 8 for $1.05678>x \geq 1.0333$. Consider first the case $x \geq 1.18731: L_{1}$ 's payoff if it acquires is then given by R\&D game 1 minus the price $p_{11}$ paid for $S_{1}$. The lowest price accepted by $S_{1}$ is $p_{O}$. If $L_{1}$ decides not to acquire in decision point 1 , the game ends in $\mathrm{R} \& \mathrm{D}$ game 4 where $L_{1}$ 's expected profit is the same and the price paid to acquire $S_{2}$ is $p_{0}$. Thus, for $x \geq 1.18731 L_{1}$ is indifferent between acquiring now or later and due to our assumption given in footnote $6 L_{1}$ acquires $S_{1}$ for $p_{11}=p_{O}$. For all other cases $L_{1}$ 's payoff if it acquires is given by R\&D game 2 and $L_{1}$ has to pay $p_{11}=p_{12}^{A}=p_{O}$. Thus, $L_{1}$ 's payoff if it acquires is

$$
\frac{\alpha x^{3} V}{(1+x)^{2}}-2 \frac{\alpha V}{(1+2 x)^{2}}
$$

$L_{1}$ 's payoff if it decides not to acquire depends on $x$. If $1.18731>x \geq 1.05678$ or $x<1.0333, L 1$ 's payoff is given by R\&D game 6 and it is

$$
\frac{\alpha V}{(1+x)^{2}}
$$

This is larger than the payoff given by 2.5) for $x<1.22364$. If $1.05678>x \geq 1.0333$, $L_{1}$ 's payoff is given by R\&D game 8 and it is

$$
\frac{\alpha V}{(1+2 x)^{2}} \text {. }
$$

This is larger than the payoff given by (2.5) for $x<1.09021$. Thus, in decision point $1 L_{1}$ bids $p_{11}=p_{O}$ and acquires $S_{1}$ for $x \geq 1.18731$ and does not acquire $S_{1}$ for $x<1.18731$.

In equilibrium the acquisition game ends thus in a symmetric duopoly in R\&D game 1 for $x \geq 1.18731$ with the two firms $\left\{L_{1}, S_{1}\right\}$ and $\left\{L_{2}, S_{2}\right\}$, in an asymmetric duopoly in R\&D game 6 for $1.18731>x \geq 1.05678$ or $x<1.0333$ with the two firms $\left\{L_{1}\right\}$ and $\left\{L_{2}, S_{1}, S_{2}\right\}$ or in a triopoly in $\mathrm{R} \& \mathrm{D}$ game 8 for $1.05678>x \geq 1.0333$ with the three firms $\left\{L_{1}\right\},\left\{S_{2}\right\}$ and $\left\{L_{2}, S_{2}\right\}$.

\footnotetext{
${ }^{12}$ Either acquired by $L_{2}$ for $x \geq 1.05678$ or $x<1.0333$ or as an independent firm in a triopoly for $1.05678>x \geq 1.0333$.
} 
The resulting sub-game perfect equilibria can be characterized as follows. For high efficiencies $(x \geq 1.18731)$ large firms bid $p_{O}$ in every decision point (except for the decision point 14 where $L_{2}$ always bids $p_{N}$ ) and the small firms accept every offer greater or equal than this offer. The reason for these equilibrium strategies is that for large efficiencies every merger is beneficial for the merging parties and it would also be beneficial to prevent the other firm from enjoying these efficiencies (off the equilibrium path strategies). For lower efficiencies large firms prefer the respectively other large firm to acquire. The positive externality (reduction of firms in the R\&D game) exceeds the negative externality that the merged firm is more efficient. For intermediate efficiencies $(1.18731>x \geq 1.05678) L_{1}$ therefore never acquires in decision point $1 . L_{2}$ has the disadvantage of making the final offer to $S_{1}$. It is more profitable for $L_{2}$ to acquire both firms than to wait and let the acquisition game end up with 3 or 4 independent firms. On the equilibrium path $L_{2}$ therefore always bids $p_{O}$ in decision points 4 and 13 and acquires $S_{1}$ and $S_{2}$. For even lower efficiencies $(1.05678>x \geq 1.0333)$ it is too costly for $L_{2}$ to acquire both small firms for $p_{O}$. However, $S_{1}$ is not accepting the lower offer $p_{N}$ in decision point 6 knowing that if it denies the offer $L_{2}$ later acquires $S_{2}$ (for $p_{N}$ ) giving $S_{1}$ profits $p_{O}$. Therefore the game ends in a triopoly for these parameter values. If efficiencies are in the lowest segment $(1.0333>x)$, it is no longer profitable for $L_{2}$ to acquire one single small firm, even for $p_{N}$. However, it is still profitable for $L_{2}$ to acquire both small firms (one for $p_{N}$, the other for $p_{O}$ ). Expecting that $L_{1}$ will not acquire $S_{2}$ if it has not already acquired $S_{1}, S_{1}$ is accepting the offer $p_{N}$ in decision point 6 in this case and the game ends in an asymmetric duopoly again. This result is summarized in the following proposition.

Although consumer welfare is not explicitly included in the model, it is possible to compare potential outcomes of the acquisition game by the probability of a successful innovation. This probability for the 4 possible outcomes of the acquisition game is

$$
p_{\text {ges }}^{1}=\alpha \cdot\left(\frac{\frac{\alpha x V}{4}}{2 \frac{\alpha x V}{4}}\right) \cdot 2=\alpha
$$

in the symmetric duopoly,

$$
p_{\text {ges }}^{2}=\left(\frac{\alpha}{x} \cdot \frac{\alpha x V}{(1+x)^{2}}+\alpha \cdot \frac{\alpha x^{2} V}{(1+x)^{2}}\right) \frac{1}{\frac{\alpha x V}{(1+x)^{2}}}=\frac{\alpha\left(1+x^{2}\right)}{x(1+x)}
$$

in the asymmetric duopoly,

$$
\begin{aligned}
p_{\text {ges }}^{3} & =\left(\left(\alpha+\frac{\alpha}{x} \cdot \frac{2 \alpha x V}{(1+2 x)^{2}}\right)+\alpha \cdot \frac{2 \alpha x V}{(1+2 x)^{2}}(2 x-1)\right) \frac{1}{2 \cdot \frac{2 \alpha x V}{(1+2 x)^{2}}+\frac{2 \alpha x V}{(1+2 x)^{2}}(2 x-1)} \\
& =\frac{\alpha\left(1+2 x^{2}\right)}{x(1+2 x)}
\end{aligned}
$$

in the triopoly and

$$
p_{\text {ges }}^{4}=2 \cdot\left(\alpha+\frac{\alpha}{x}\right) \frac{\frac{\alpha \cdot V}{16}}{4 \cdot \frac{\alpha \cdot V}{16}}=\frac{\alpha(1+x)}{2 x}
$$

in the initial situation with four independent firms. 
Proposition 2. The Probability of a successful innovation is highest in the symmetric duopoly, followed by the triopoly and the asymmetric duopoly. Chances are lowest in the initial situation with four independent firms.

Proof. The elements of the proposition are shown consecutively:

$$
\begin{aligned}
p_{\text {ges }}^{1}-p_{\text {ges }}^{3} & =\alpha-\frac{\alpha\left(1+2 x^{2}\right)}{x(1+2 x)}=\frac{\alpha(x-1)}{x(1+2 x)}>0, \\
p_{\text {ges }}^{3}-p_{\text {ges }}^{2} & =\frac{\alpha\left(1+2 x^{2}\right)}{x(1+2 x)}-\frac{\alpha\left(1+x^{2}\right)}{x(1+x)}=\frac{\alpha(x-1)}{1+3 x+2 x^{2}}>0, \\
p p_{\text {ges }}^{2}-p_{\text {ges }}^{4} & =\frac{\alpha\left(1+x^{2}\right)}{x(1+x)}-\frac{\alpha(1+x)}{2 x}=\frac{\alpha(x-1)^{2}}{2 x(1+x)}>0 .
\end{aligned}
$$

Thus, $p_{\text {ges }}^{1}>p_{\text {ges }}^{3}>p_{\text {ges }}^{2}>p_{\text {ges }}^{4}$.

The intuition for this result is that the total probability of a successful innovation is influenced by two effects in the model: First, a higher investment by firms with a high $R \& D$ efficiency and second, elimination of firms with low R\&D efficiency in the R\&D games. A policy that favors at least one acquisitions is therefore beneficial for innovation in this model.

For all asymmetric cases, payoffs are larger for $L_{1}$ than for $L_{2}$. In the symmetric case, payoffs are identical. Thus, there is a first-mover advantage in the game for large firms. Small firms' payoffs are identical for $x \geq 1.05678$. If $1.05678>x>1.0333, S_{1}$ can profitably deny a low offer of $L_{2}$ and get a higher profit as an independent firm than $S_{2}$ that gets acquired in equilibrium. For even lower efficiencies $S_{1}$ can no longer profitably deny a low offer and the situation turns around as then the price of $S_{2}$ that gets acquired later is higher. Thus, there is no clear first-mover advantage or disadvantage for small firms.

\subsection{Robustness}

In this section I check for the sensitivity of results to the proposed timing structure in the acquisition game. I first generally discuss the strategic effect of the known timing structure, especially that $L_{1}$ firm knows that there is still a bidding decision of $L_{2}$ after its second bid while $L_{2}$ knows that the acquisition game ends after its second bid. Then I analyze an alternative modeling with simultaneous acquisition decisions.

\subsubsection{Timing general}

In this section I analyze the impact of the timing structure on the game's results. I discuss the influence of timing on firms' decisions.

In section 2.1.2 I found that payoffs for $L_{1}$ and $L_{2}$ differ for low efficiencies and there is a first-mover advantage since $L_{1}$ can simply wait to let $L_{2}$ acquire one or both small firms and benefit from the externalities of the merger. It is crucial for $L_{1}$ 's strategic decision to wait that it knows that $L_{2}$ cannot simply wait as well but will acquire either 
one or both small firms since this is more profitable than not acquiring at all and leaving the situation with four independent firms for $L_{2}$. If there was no such final bidding round in the acquisition game, a hold up problem between $L_{1}$ and $L_{2}$ would occur: The first large firm to acquire would make less expected profits and thus both firms would wait for the other firm to move.

\subsubsection{Simultaneous Acquisitions}

A way to react to the problem of a first-mover advantage in the acquisition game which is somehow critical since firms are ex ante symmetric - is to let large firms decide simultaneously whether to acquire one of the small firms or not 13 That is described in this section.

If both large firms decide to acquire, the number of firms is reduced from 4 to 2 . Both merged firms enjoy the same efficiencies and the resulting situation is symmetric. If only one firm decides to acquire, we have an asymmetric situation with one large, one small and the merged firm. If no large firm decides to acquire, the situation remains unchanged. Investments and expected profits depend on the resulting situation.

\section{Both large firms acquire}

In this situation only 2 identical firms remain in the market. Both have small firms' R\&D efficiency $\alpha_{S}$ and large firms' product market efficiency $V_{L}=x \cdot V_{S}$. The situation is equivalent to the situation in $\mathrm{R} \& \mathrm{D}$ game 1 described above. Therefore resulting profits are

$$
\frac{\alpha x V}{4}
$$

\section{Only one large firm acquires}

This is an asymmetric situation with one large one small and the merged firm. The situation is equivalent to the R\&D game 3 described above. Resulting profits are thus

$$
\frac{\alpha x V}{(1+2 x)^{2}}(2 x-1)^{2}
$$

for the merged firm and

$$
\frac{\alpha V}{(1+2 x)^{2}}
$$

for the outsiders.

\section{No large firm acquires}

In this case, there are 4 firms in the market, two small firms with higher R\&D efficiency and two large firms with superior product market efficiency. The situation is equivalent to R\&D game 9 and therefore expected profits are

$$
\frac{\alpha V}{16}
$$

both for large and small firms.

\footnotetext{
${ }^{13} \mathrm{I}$ abstract from the coordination problem which small firm is acquired by which large firm.
} 


\subsubsection{Equilibria with simultaneous acquisitions}

Taking optimal decisions in the investment stage as given, expected profits for the 3 situations described above are given in the following matrix. To make results comparable I show the combined profits of one large and one small firm in the non-acquisition cases 14 Payoffs are summarized in the following matrix. Looking at the payoffs for $L_{1}$ if $L_{2}$

\begin{tabular}{||l|l|cc|cc||}
\hline & & \multicolumn{3}{|c||}{$L_{2}$} \\
\hline & & \multicolumn{2}{|c|}{ Acquire } & \multicolumn{2}{c||}{ Not Acquire } \\
\hline$L_{1}$ & Acquire & $\frac{\alpha x V}{4}$ & $\frac{\alpha x V}{4}$ & $\frac{\alpha x V}{(1+2 x)^{2}}(2 x-1)^{2}$ & $2 \frac{\alpha V}{(1+2 x)^{2}}$ \\
\hline & Not Acquire & $2 \frac{\alpha V}{(1+2 x)^{2}}$ & $\frac{\alpha x V}{(1+2 x)^{2}}(2 x-1)^{2}$ & $2 \frac{\alpha V}{16}$ & $2 \frac{\alpha V}{16}$ \\
\hline
\end{tabular}

Table 1: Payoffs for the simultaneous acquisition game

acquires, we see that

$$
\frac{\alpha x V}{4}-2 \frac{\alpha V}{(1+2 x)^{2}}=\frac{1}{4} \alpha V\left(x-\frac{8}{(1+2 x)^{2}}\right)>0
$$

for $x>1$. Thus, it is always optimal to acquire if the other large firm is acquiring. If $L_{2}$ does not acquire, we see that

$$
\frac{\alpha x V}{(1+2 x)^{2}}(2 x-1)^{2}-2 \frac{\alpha V}{16}=\alpha V\left(\frac{(2 x-1)^{2} x}{(1+2 x)^{2}}-\frac{1}{8}\right)>0
$$

for $x>1.0333$. Thus, for $x>1.0333$ "Acquire" is a strict dominant strategy for large firms. If $x<1.0333$, the game has two Nash-Equilibria in pure Strategies (Acquire, Acquire) and (Not Acquire, Not Acquire). The intuition for this result is that with enough efficiencies a merger by itself is profitable and therefore each of the large firms wants to acquire a small firm. The result is therefore comparable to the one with sequential acquisitions. If efficiencies are low, the negative effect that two former independent firms now operate as one overweighs the efficiency effect such that firms prefer not to merge unless the other firms merge as well.

\section{Conclusion}

This paper analyzes innovation incentives for large and small firms in different strategic contexts. I model a patent contest with 4 firms and a fixed prize for the winner. Prior to the innovation stage large firms play a merger game. In the first setup, large firms sequentially decide on acquiring small firms in order to combine the respective advantages of each type of firm. While the reduction of competitors exhibits a positive effect on the outsiders of that merger, the merged firm is now as least as good as the competitors in one sector and better in the other. I show that if the merger creates large efficiencies firms prefer to merge. For low efficiencies on the other hand large firms prefer to wait

\footnotetext{
${ }^{14}$ This is equivalent to an analysis with a bidding price $p_{0}$ if the other large firm acquires and a price $p_{N}$ if the other large firm does not acquire.
} 
and let the other firm acquire. In the sequential acquisition game there is a first-mover advantage since the second large firm prefers to acquire at least one small firm than to leave the market unchanged with four independent firm. If the acquisition decision is simultaneous, results are comparable.

My model has several limitations. Firstly, I use a contest model in the R\&D game. This simplification allows to focus on the different effects a merger has on different types of firms and to get closed form solutions in all analyzed cases. This comes to the expense that timing effects of R\&D investments cannot be analyzed.

Secondly, I assume product market profits to be fixed. While this simplification is used in various papers analyzing $R \& D$ incentives, it is still a critical assumption. This is particularly relevant as I model acquisitions, i.e. events that change the market structure and are therefore likely to have an effect on the product market and thus on firms' profits.

Finally, acquisitions are modeled as simple as possible. It would be possible to account for inefficiencies in the acquisition and not to give the merged firm the complete advantages of both types of firms in the contest. While these changes would lead to a dramatic increase in the complexity of the model - particularly with regards to the sequential acquisition game - I think that it would not lead to more insights. On the contrary, it could hinder the insights with respect to the effects I want to focus on.

The results of my paper lead to questions concerning the organization of $R \& D$ in large and small companies. Why do small and large firms have these advantages and how can the firms strategically act to improve their advantages or to reduce disadvantages? Furthermore, I totally abstracted from reorganization issues connected with the merger. What exactly happens after a merger? Which advantages can be kept, which might be lost and what trade offs does the merged firm face. A theoretical model that answers these questions would be very helpful to improve understanding of different $R \& D$ approaches. What is more, it could help to allocate (public) R\&D funds to the most promising approaches.

\section{References}

[1] Acs, Z.J. and D.B. Audretsch (1990): Innovation and Small Firms, Cambridge: MIT Press.

[2] Arrow K.J. (1962): Economic Welfare and the Allocation of Resources for Invention in Richard R. Nelso (ed.), The rate and direction of inventive activity, Princeton, NJ: Princeton University Press, 1962, pp. 609-626.

[3] Bittlingmayer, G. (1985): Did antitrust policy cause the Great Merger Wave?, Journal of Law and Economics,28 pp. 77-118

[4] Coase R.H. (1937): The Nature of the Firm, Economica, 4, pp. 386-405. 
[5] Cohen W.M. and R.C. Levin (1989): Empirical Studies of Innovation and Market Structure, in R. Schmalensee and R.D. Willig (eds.) Handbook of Industrial Organization, Amsterdam: Elsevier Science Publishers, pp. 1059-1107.

[6] Competition Commission (2004): Carl Zeiss Jena GmbH and Bio-Rad Laboratories Inc; A report on the proposed acquisition of the microscope business of Bio-Rad Laboratories Inc.

[7] Denicolò, V. (1996): Patent Races and optimal Patent Breadth and Length, The Journal of Industrial Economics, 3, pp. 249-265.

[8] Dixit, A.K. (1987): Strategic behavior in contests, American Economic Review, 77,pp. 891-898.

[9] Dorazelski, U. (2003): An R\&D Race with Knowledge Accumulation, Rand Journal of Economics, 1, pp. 20-42.

[10] Ernst, H. and J. Vitt (2000): The influence of corporate acquisitions on the behaviour of key inventors, RED Management, 30, pp. 105-119.

[11] Harris, C. and J. Vickers (1985): Patent Races and the Persistence of Monopoly, The Journal of Industrial Economics, 33, pp. 461-481.

[12] Hörner, J. (2004): A Perpetual Race to Stay Ahead, Review of Economic Studies, 71, pp. 1065-1088.

[13] Gilbert, R.J. and D.M.G. Newbery (1982): Preemptive Patenting and the Persistence of Monopoly, The American Economic Review, 72, pp. 514-526.

[14] Jost, P.J. and C. van der Velden (2006): Mergers in patent contest models with synergies and spillovers, Schmalenbach Business Review, 58, pp. 157-179.

[15] Kamien, M.I. and N.L. Schwartz (1982): Market Structure and Innovation, Cambridge: Cambridge University Press.

[16] Lindholm, A. (1996a): An Economic System of Technology-Related Acquisitions and Spin-offs, University of Cambridge, ESRC Centre for Busines Research,Working Paper 33.

[17] Lindholm, A. (1996b): Acquisition and Growth of Technology-based Firms, University of Cambridge ESRC Centre for Busines Research,Working Paper 47.

[18] Nilssen, T. and L. Sørgard (1998): Sequential horizontal mergers, European Economic Review, 42, pp. 1683-1702.

[19] Reinganum, J. (1989): The timing of innovation: Research, Development and Diffusion, in R. Schmalensee and R. Willig (eds.), Handbook of Industrial Organization, North Holland, New York, 1989, pp. 849-908. 
[20] Roberts, E.B. and C.A. Berry (1985): Entering New Businesses: Selecting Strategies for Success, Sloan Management Review, (Spring), pp 3-17.

[21] Rothwell, R. and W. Zegveld (1982): Innovation and the Small and Medium-Sized Firm, London, Frances Pinter

[22] Rothwell, R. (1989): Small Firms, Innovation and Industrial Change, Small Business Economics, 1, pp. 21-38.

[23] Salant, S.W., S. Switzer, and R.J. Reynolds (1983): Losses from horizontal merger: The effects of an exogenous change in industry structure on Cournot-Nash equilibrium, Quarterly Journal of Economics, 98, pp. 185-199.

[24] Santarelli, E. and A. Sterlacchini (1990): Innovation, Formal vs. Informal R\&D, and Firm Size: Some Evidence from Italian Manufacturing Firms, Small Business Economics, 2, pp. 223-228.

[25] Stigler, G.J. (1950): Monopoly and oligopoly by merger, Americean Economic Review, Papers and Proceedings 40, pp. 23-34.

[26] Van Dijk, B., R. den Hertog, B. Menkveld and A.R. Thurik (1997): Some New Evidence on the Determinants of Large- and Small-Firm Innovation, Small Business Economics, 9, pp. 335-343.

[27] Van Wegberg, M. (1994): Why do mergers occur inwaves? Business cycles, bandwagons and the merger for market power paradox. Research Memorandum RM/0/94022, METEOR, University of Limburg, Maastricht.

[28] Veugelers R. and B. Cassiman (1999): Make and Buy in Innovation Strategies: Evidence from Belgian Manufacturing Firms, Research Policy, 28, pp. 63-80.

[29] Zachau (1987): Mergers in the Model of an R\&D Race, University of Bonn, Sonderforschungsbereich 303, Discussion Paper No. A 139. 